\title{
DESAIN SISTEM KALIBRATOR DAN DETEKTOR PERGERAKAN TANAH DI LAHAN MIRING
}

\author{
Riska Ekawita ${ }^{a}$, Elfi Yuliza, Halauddin, Lizalidiawati \\ Jurusan Fisika, FMIPA, Universitas Bengkulu \\ Jl. WR. Supratman Kandang Limun, Bengkulu, 38371 \\ Email: a)aquriska@gmail.com
}

\begin{abstract}
Abstrak
Pengamatan pergerakan tanah menggunakan sistem sensor merupakan upaya efektif yang dapat dilakukan dalam mengurangi resiko bencana longsor. Pada penelitian ini dikembangkan sistem detektor pergerakan tanah menggunakan sensor accelerometer. Untuk mengurangi kesalahan pembacan sensor, dilakukan perancangan sistem kalibrator. Secara umum, sistem kalibrator terdiri dari motor dan driver motor yang bergerak secara diskrit. Detektor kemiringan menggunakan sensor accelerometer 3 axis dan mikrokontroler. Karakteristik kalibrator yang dikembangkan mampu menguji sensor dalam dalam dua axis, sehingga untuk sensor 3 axis dapat dilakukan secara manual. Berdasarkan hasil uji kalibrasi dan uji performa sensor pada model fisis skala laboratorium, sistem sensor telah menunjukan hasil yang baik dan sesuai digunakan untuk sistem pengamatan pergerakan tanah. Sensor accelerometer memiliki resolusi hingga $0,386 \%$ step sehingga setiap perubahan kecil yang terjadi dapat terdeteksi dengan baik pada sensor
\end{abstract}

Kata-kata kunci: accelerometer; kalibrasi; kemiringan; mikrokontroler.

\begin{abstract}
Observation of soil movement using sensor system is an effective effort that can be done in reducing the risk of landslide disaster. In this research, it has been developed soil movement detector system using accelerometer sensor. The calibrator system is designed to reduce the error sensor. Generally, calibrator system consists of motor and driver motor that move discretely. The inclined plane detector used 3 axis accelerometer and microcontroller. The developed calibrator characteristics are capable of testing the sensors within two axis, so for 3 axis sensors can be done manually. Based on the results of calibration and sensor performance test on the laboratory scale physical model, the sensor system has shown good result and suitable to be used for observation system of the soil movement on inclined plane. The accelerometer sensor has a resolution of up to $0.386 \mathrm{o} / \mathrm{step}$ so that any minor changes that occur can be detected properly on the sensor.
\end{abstract}

Keywords: accelerometer; calibration; inclined plane; microcontroller.

\section{PENDAHULUAN}

Bencana pergerakan tanah atau lebih dikenal dengan longsor merupakan bencana dengan frekuensi kejadian terbesar kedua dalam 5 tahun terakhir (dibi.bnpb.go.id). Kejadian ini telah menimbulkan berbagai kerugian seperti hilangnya nyawa, kerugian material dan lain-lain.

Salah satu upaya yang dapat dilakukan dalam meminimalisir resiko kejadian yang berkaitan dengan pergerakan tanah adalah pengembangan sistem deteksi dini pergerakan tanah, baik itu skala laboratorium seperti pengukuran deformasi tanah [1-2] maupun skala lapangan. Apabila diambil 
studi kasus pada kejadian longsor secara umum, pemahaman dalam bidang kinematika, dinamika, geomorfologi, topografi dan geohidrologi dapat mengurangi resiko kejadian longsor [3-7]. Secara umum, pergerakan tanah terjadi dengan sangat cepat hingga sangat lambat. Berdasarkan historis kejadian longsor di Indonesia, peningkatan air hujan yang berinfiltrasi ke dalam tanah menjadi pemicu utama diberbagai kejadian longsor.

Belum tersedianya teknologi mapan yang mampu mendeteksi pergerakan tanah merupakan permasalahan yang harus dicarikan solusinya agar dampak bencana dapat diminimalisir. Oleh karena itu, pada penelitian ini dikembangkan sistem pengukur pergerakan tanah dalam 3 arah pergerakan (X, Y dan Z) dengan memanfaatkan sensor accelerometer. Sistem ini dilengkapi dengan pengembangan sistem kalibrator sensor kemiringan dan sistem pengujian menggunakan model fisis skala laboratorium.

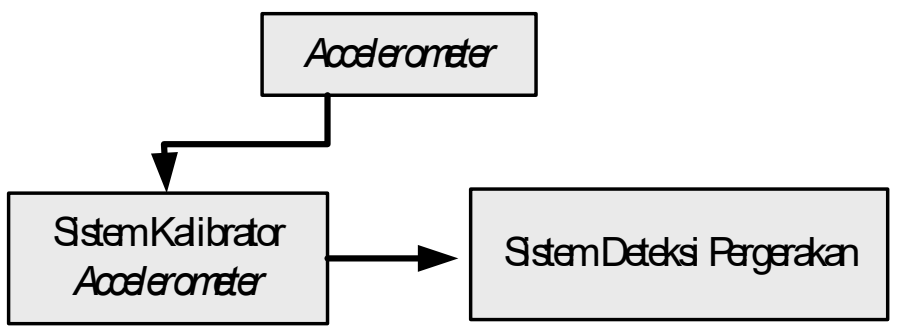

GAMBAR 1. Diagram blok sistem instrumentasi

\section{METODE PENELITIAN}

Secara garis besar tahapan rancangan sistem deteksi pergerakan tanah dibagi atas dua bagian yaitu pertama perancangan sistem kalibrator untuk mengkalibrasi sensor yang digunakan sebagai detektor kemiringan atau pergerakan tanah. Kedua yaitu pengujian sistem deteksi tanah secara keseluruhan menggunakan model fisis yang telah dikembangkan. Gambar 1 merupakan diagram blok sistem instrumentasi yang dibangun.

Sistem kalibrator dibuat untuk proses kalibrasi sensor kemiringan yang digunakan (accelerometer), untuk mengurangi error yang mungkin terjadi dalam penggunaan sensor accelerometer serta mengetahui respon keluaran sensor terhadap perubahan kemiringan yang dilakukan. Sedangkan sistem deteksi berbasis accelerometer dibangun oleh beberapa bagian yaitu pengkondisi sinyal yang mengolah sinyal berasal dari keluaran sensor untuk dapat dijadikan masukan pada bagian berikutnya, yaitu analog to digital converter (ADC). ADC yang digunakan disini merupakan ADC 10 bit yang tersedia pada tipe mikrokontroler yang digunakan pada sistem. Bagian berikutnya adalah mikrokontroler yang merupakan kontrol dari seluruh bagian instrumen dan display yang menampilkan nilai hasil pengukuran.

\section{Sistem kalibrator}

Tahapan ini diawali dengan rancang bangun sistem kalibrator yang terdiri dari motor dan drivernya, mikrokontroler, liquid crystal display (LCD), komponen penggerak yang juga berfungsi sebagai dudukan sensor ketika dikalibrasi dan gear untuk meningkatkan resolusi gerak kalibrator. Tampilan sistem kalibrator terlihat pada Gambar 2. 


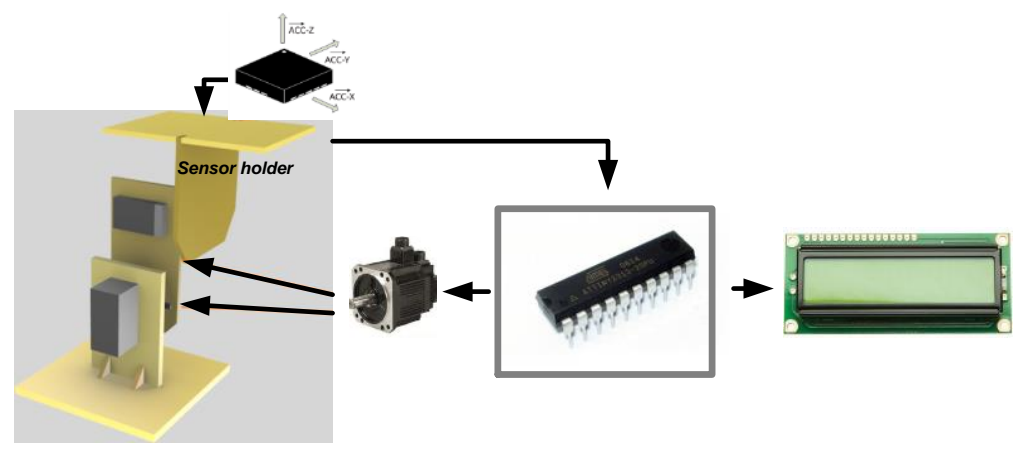

GAMBAR 2. Tampilan kalibrator

Pada proses kalibrasi, sensor yang akan diuji ditempatkan pada sensor holder dan diberikan perintah pada mikrokontroler untuk bergerak sejauh derajat tertentu kearah timur-barat. Karena sistem pengukuran dalam dua dimensi, sehingga tidak semua axis dari accelerometer yang dapat diuji. Pengujian dapat dilakukan dengan mengubah posisi sensor pada sensor holder secara manual.

\section{Sistem deteksi pergerakan kemiringan}

Pengujian performa sensor dilakukan setelah tahap kalibrasi dengan sistem kalibrator dilakukan. Oleh karena itu dibangunlah kontur yang memiliki kemiringan sebagaimana dapat mewakili model longsor, seperti pada terlihat pada Gambar 3.

Model yang digunakan merupakan wadah yang terbuat dari akrilik dengan ukuran250x45x40 cm. Wadah ini dapat dimiringkan dengan variasi sudut yang diinginkan. Pada model ini juga digunakan air rembesan yang berfungsi sebagai pemicu terjadinya pergerakan tanah. Pergerakan inilah yang kemudian diukur melalui respon yang terbaca pada sensor.

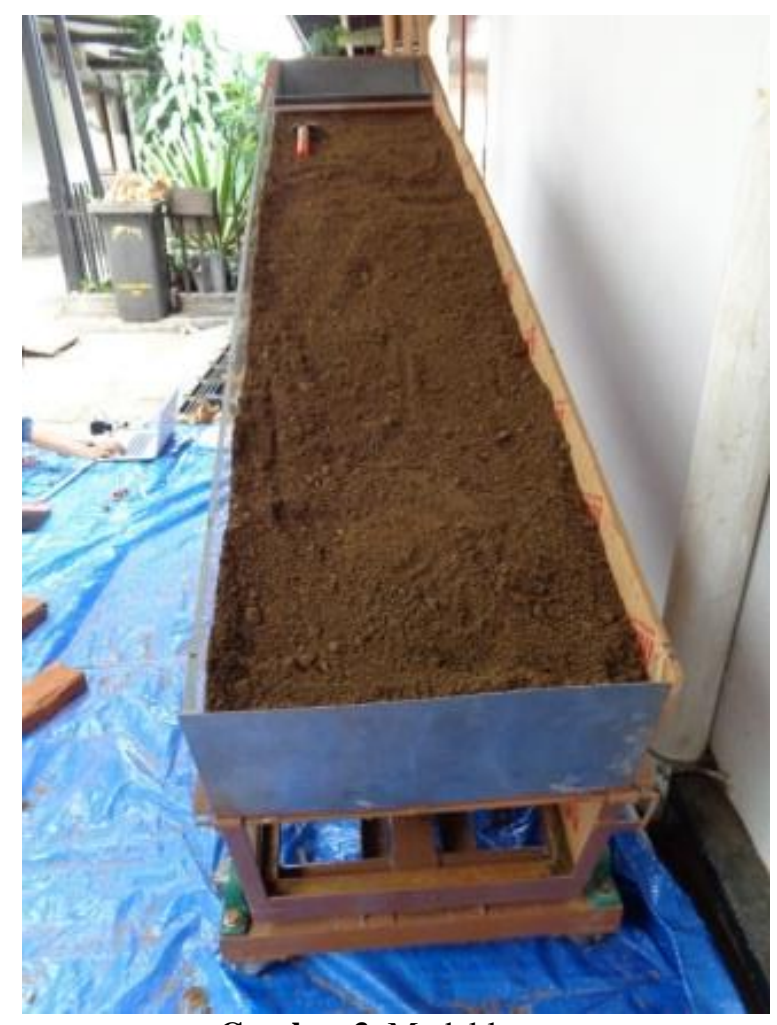

Gambar 3. Model lereng 


\section{HASIL DAN PEMBAHASAN}

\section{Hasil kalibrasi}

Gambar 4 merupakan hasil pengujian gerak motor yang akan digunakan pada sistem kalibrator. Untuk dapat bergerak sejauh $90^{\circ}$ maka banyak step yang terjadi adalah sejumlah 233 steps. Dari hubungan ini menghasilkan resolusi sistem kalibrator sebesar $0,386 \%$ step. Atau untuk pergerakan setiap step akan terjadi perubahan sudut sebesar $0,386^{\circ}$.

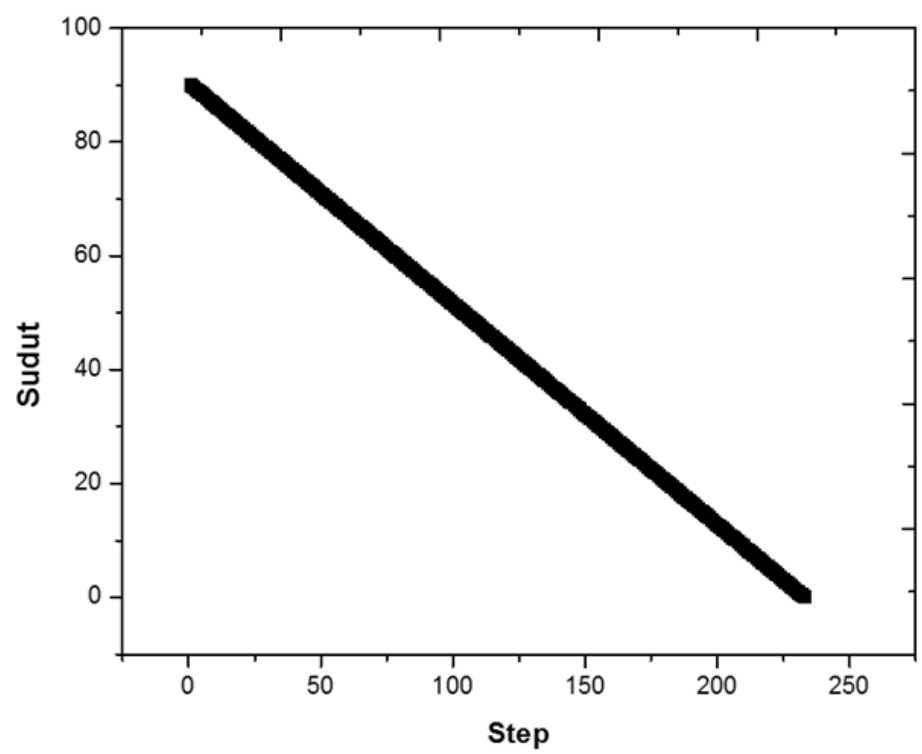

GAMBAR 4. Hubungan perubahan sudut dan step

Tahapan selanjutnya adalah kalibrasi accelerometer menggunakan kalibrator yang telah dikembangkan. Secara umum hasil kalibrasi untuk accelerometer ditunjukan pada Gambar 5. Hasil pengukuran dan kalibrasi sensor untuk gerak rotasi sejauh $90^{\circ}$ menunjukan hasil yang tidak sepenuhnya linear. Sensor accelerometer menunjukan respon linear untuk sudut-sudut besar, sedangkan untuk sudut-sudut kecil relatif tidak linear. Di samping itu, Gambar 5 juga menunjukan banyaknya noise yang terjadi dari hasil kalibrasi. Noise dihasilkan dari getaran yang terjadi saat mengkalibrasi sensor. Accelerometer selain sebagai pengukur kemiringan, juga dimanfaatkan sebagai sensor getaran. Oleh karena getaran yang terjadi selama proses pengukuran yang diakibatkan oleh stabilitas sistem kalibrasi menghasilkan respon sensor seperti yang ditunjukan pada Gambar 5. Untuk sistem kalibrasi yang lebih stabil, seharusnya memiliki getaran yang sangat kecil. 
(a)

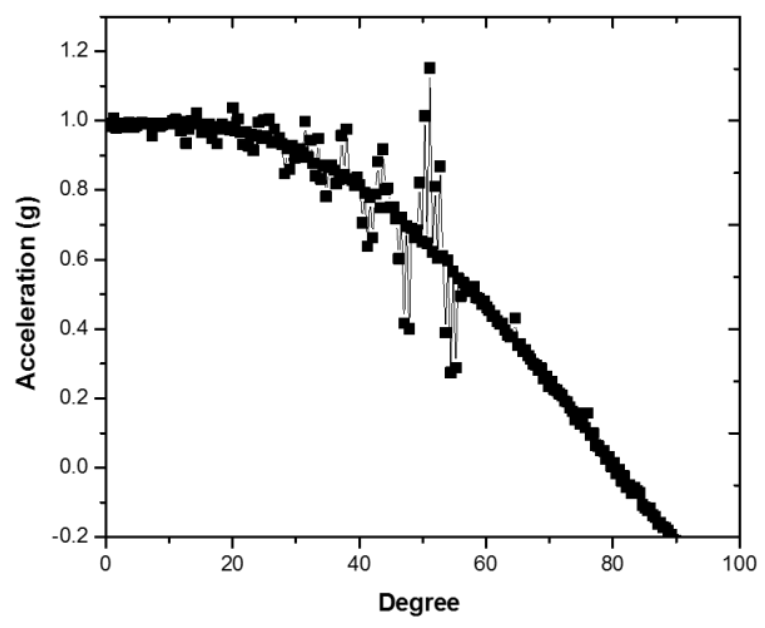

(b)

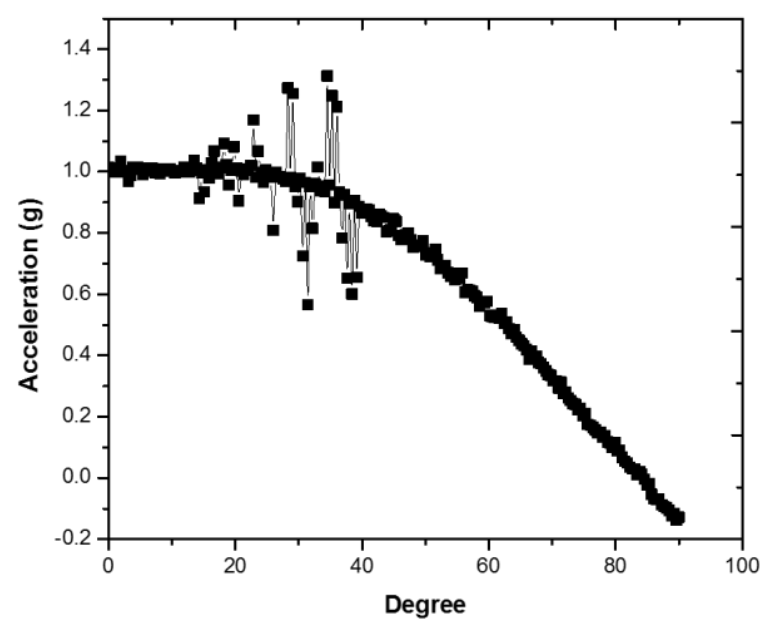

GAMBAR 5. Karakteristik respon sensor menggunakan sistem kalibrator (a) sumbu X, (b) sumbu Y

Pada penelitian ini, accelerometer yang digunakan adalah accelerometer 3 axis, sehingga hasil kalibrasi seharusnya ditampilkan untuk 3 axis. Sedangkan karakteristik kalibrasi menunjukan hasil kalibrasi hanya untuk sumbu X dan Y. Hal ini dikarenakan karakteristik pengukuran menggunakan sistem 1 dimensi dan dua dimensi. Untuk memudahkan dalam pemahaman dapat diilustrasikan menggunakan Gambar 6.

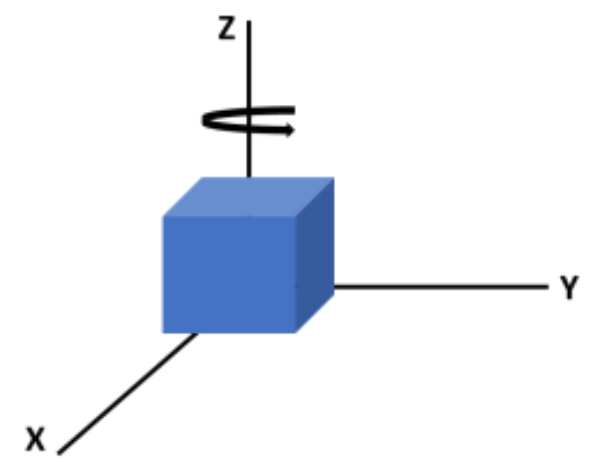

GAMBAR 6. Ilustrasi rotasi 3 axis

Untuk benda dengan 3 sumbu, apabila dilakukan rotasi pada salah satu sumbu maka sumbu yang menjadi sumbu putar tidak akan mengalami perubahan respon. Seperti diilustrasikan pada Gambar 6, apabila sumbu $\mathrm{Z}$ dijadikan sebagai sumbu putar maka ketika benda diputar pada sumbu $\mathrm{Z}$ maka yang mengalami perubahan respon adalah sumbu $X$ dan $Y$. Karakteristik ini juga berlaku jika sumbu putar adalah X maka yang berubah adalah $\mathrm{Y}, \mathrm{Z}$, begitu juga jika sumbu putar $\mathrm{Y}$ yang berubah adalah sumby Z,X. Untuk mengetahui respon secara keseluruhan, dapat dilakukan dengan mengubah posisi sensor pada sensor holder secara manual. Namun secara umum respon sensor untuk setiap sumbu menunjukan karakteristik yang sama. Untuk hasil yang lebih baik, dapat dilakukan pengembangan sistem kalibrasi lebih lanjut untuk mendapatkan hasil kalibrasi dengan noise yang kecil.

\section{Hasil pengujian model lereng}

Pada pengujian sensor dengan model lereng, digunakan 4 sensor accelerometer (Gambar 7). Hal ini bertujuan untuk mengetahui respon perubahan setiap titiknya. Empat sensor accelerometer ditempatkan pada sebuah pipa untuk dapat terkoneksi dengan mikrokontroler. 


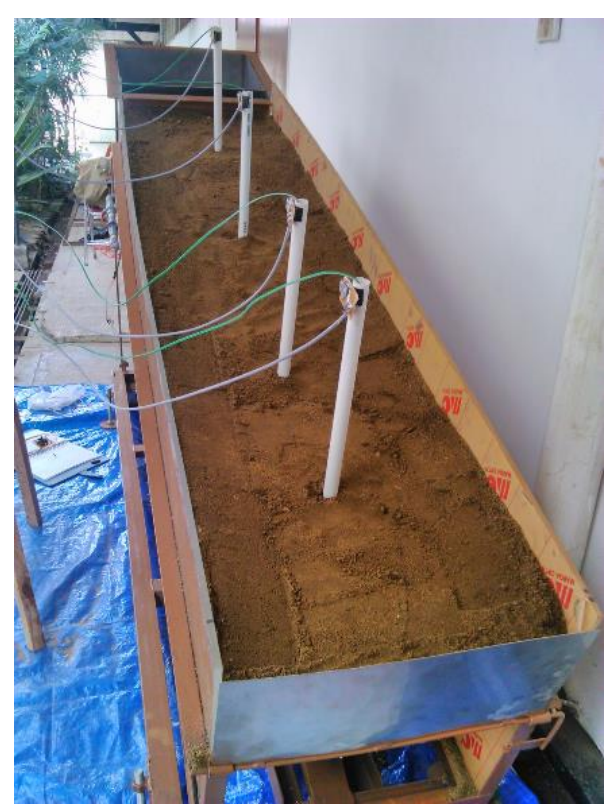

GAMBAR 7. Pengujian sensor pada model lereng

Kemiringan lereng adalah $24,6^{\circ}$ dan sensor disebar pada 4 titik untuk melihat respon perubahan pada selang waktu tertentu. Respon perubahan sensor ditunjukan pada Gambar 8.

(a)

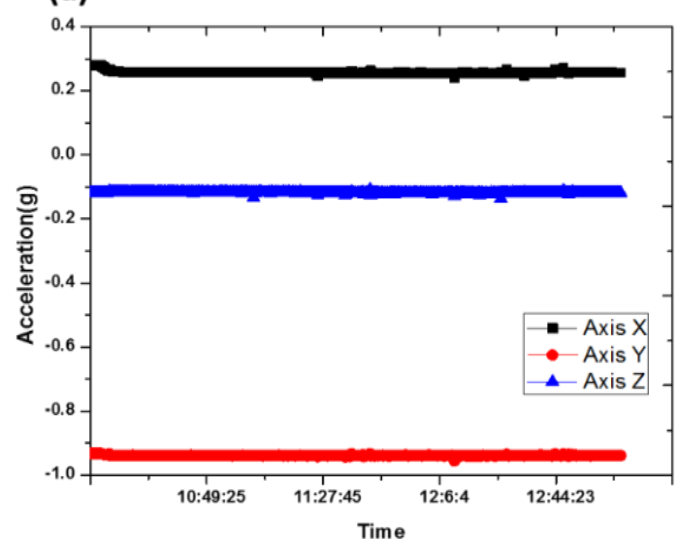

(c)

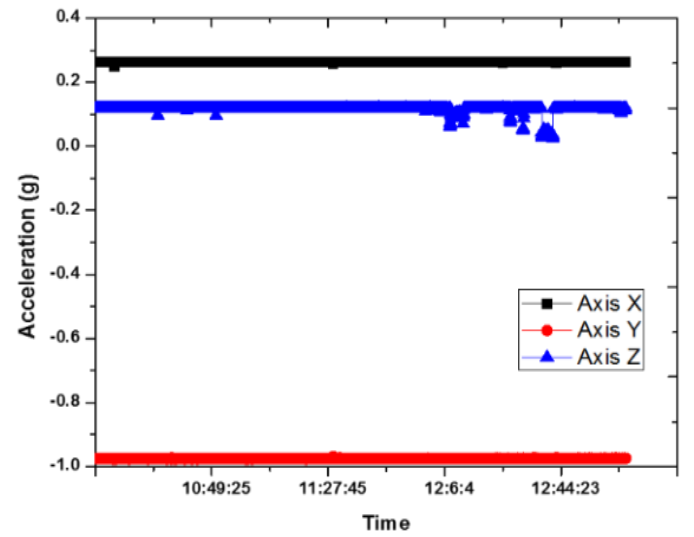

(b)

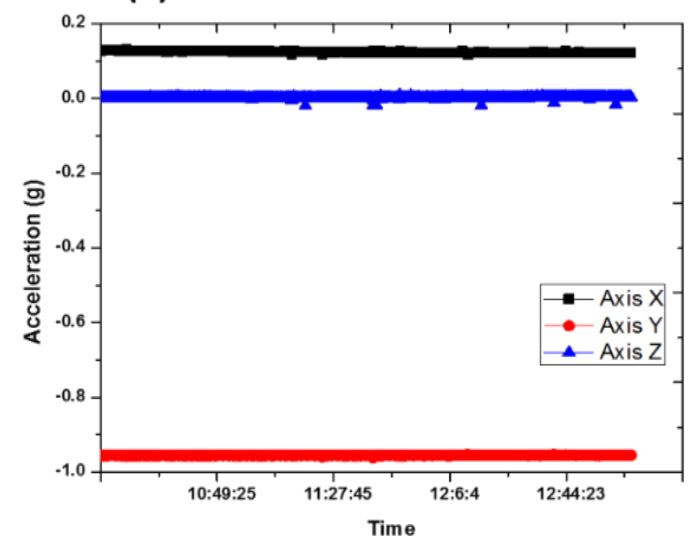

(d)

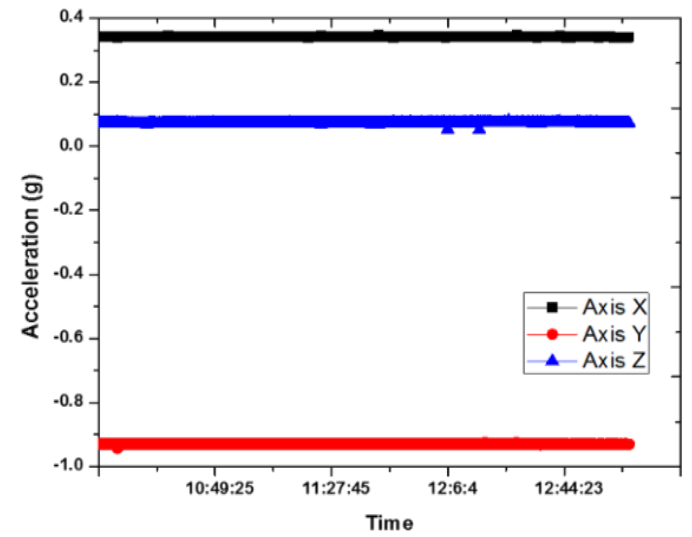

GAMBAR 8. Respon perubahan sensor (a) sensor 1, (b) sensor 2, (c) Sensor 3 dan (d) sensor 4 
Berdasarkan hasil yang diperoleh, tidak terjadi pergerakan yang signifikan sehingga respon sensor relatif sama untuk selang waktu 2 jam pengukuran. Sedangkan apabila dibandingkan respon sensor untuk setiap posisi dapat diketahui bahwa respon pembacaan sensor dipengaruhi oleh posisi dan kemiringan sensor. kemiringan posisi akan mempengaruhi pembacaan setiap sumbunya.

Pada kasus pengukuran ini, diambil respon sensor 1 dan sensor 2. Kedua sensor ini memiliki respon yang sama untuk sumbu $\mathrm{Y}$ dan berbeda untuk sumbu lainnya. Kasus ini juga terjadi pada sensor 3 dan sensor 4. Untuk mengetahui karakteristik kontur lereng menggunakan accelerometer dapat diketahui melalui perbandingan pembacaan setia sumbu. Sedangkan untuk mendeteksi pergerakan tanah dilakukan dengan melihat perubahan respon setiap sumbu dari keadaan awal.

\section{KESIMPULAN}

Telah dilakukan serangkaian tahapan untuk menghasilkan sistem pengukur pergerakan tanah dan kemiringan berbasis mikrokontroler. Sistem menggunakan sensor accelerometer. Berdasarkan hasil uji kalibrasi dan uji performa sensor pada model fisis skala laboratorium, sistem sensor telah menunjukan hasil yang baik dan sesuai digunakan untuk sistem pengamatan pergerakan tanah. Sensor accelerometer memiliki resolusi hingga 0,386o/step sehingga setiap perubahan kecil yang terjadi dapat terdeteksi dengan baik pada sensor. Penggunaan sensor accelerometer juga memiliki potensi untuk mendeteksi getaran yang terjadi

\section{UCAPAN TERIMAKASIH}

Terimakasih kepada pihak pemberi dana penelitian (Dana PNBP FMIPA UNIB 2016) yang telah membantu membiayai bagian dari penelitian ini.

\section{DAFTAR ACUAN}

[1]R. Ekawita, et al, "A simple and inexpensive vertical deformation measurement system for soil compression tests," AIP Conference Proceeding, vol. 1589, pp. 104-107, 2014.

[2] R. A. Salam, et al, "Design and Implementation of wireless sensor network on ground movement detection system," Proceeding of IC3INA IEEE, pp. 89-92, 2015.

[3] S. Mandal and R. Maiti, "Assessing the triggering rainfall induced landslip events in the shivkhola watershed of darjiling Himalaya, west Bengal," European Journal of Geography, vol. 4. pp. 21-37, 2013.

[4] V. Greif and J. Vicko, "Monitoring of Post Failure Landslide Deformation by the PS-InSAR technique at Lubietova in Central Slovakia, Environ., Earth Sci., vol. 66 (6), pp. 1585-1595, 2012.

[4] V. F. De Blasio, "Introduction to the physics of landslides," New York, Springer, 2011.

[5] A. Garcia, et al, "Landslide monitoring with high resolution tilt measurements at the Dollendorfer Hardt landslide Germany," Geomorphology, vol. 120, 2010.

[6] T. Uchimura, et al, "Simple Monitoring Method for Precaution of Landslides Watching Tilting and water Contents on Slopes Surface," Landslides, vol. 7(3), pp. 351-357, 2010. 
